\title{
Macular edema in Vogt-Koyanagi-Harada syndrome treated with antiangiogenic therapy. Case report
}

\section{Edema macular en síndrome de Vogt-Koyanagi-Harada tratado con terapia antiangiogénica. Informe de un caso}

Manuela A. Flores-Peraza ${ }^{1 *}$, Pedro I. González-Camarena², Gerardo Martínez-del Villar ${ }^{3}$, Rita Rios-Prado 4 and Ernesto A. Díaz-del-Castillo-Martín ${ }^{5}$

${ }^{1}$ Retina and Vitreous; ${ }^{2}$ Neuro-ophthalmology department; ${ }^{3}$ Retina and Vitreous department; ${ }^{4}$ Uvea department; ${ }^{5}$ Ophthalmology department. Ophthalmology Hospital, Centro Médico Nacional Siglo XXI, Mexico City, Mexico

\begin{abstract}
$50 \%$ of patients with syndrome Vogt-Koyanagi-Harada presents ocular complications, 5-10\% have neovascular membrane and macular edema. We present a 39-year-old woman with macular edema secondary to syndrome Vogt-Koyanagi-Harada, treated with antiangiogenic intravitreal injections and its evolution was objectively followed with optical coherence tomography. Discussion: Antiangiogenic intravitreal injections are an alternative for the treatment of macular edema secondary to inflammatory eye diseases compared to conventional therapy with sub-Tenon steroids and intravitreal injections.
\end{abstract}

Key words: Vogt-Koyanagi-Harada syndrome. Macular edema. Optical coherence tomography. Antiangiogenic treatment. Ranibizumab.

\section{Resumen}

El 50\% de los pacientes con síndrome de Vogt-Koyanagi-Harada presenta complicaciones oculares; de estos, el 5-10\% presenta membrana neovascular y edema macular, como la paciente que presentamos. Paciente femenino de 39 años de edad con edema macular y síndrome de Vogt-Koyanagi-Harada de un año de evolución. Se aplicaron 2 inyecciones intravitreas de fármacos antiangiogénicos y su evolución fue seguida objetivamente con tomografía de coherencia óptica. Discusión: Las inyecciones intravítreas de antiangiogénicos son una alternativa en el tratamiento del edema macular secundario a enfermedades oculares inflamatorias comparado con la terapia convencional con inyecciones de esteroides subtenonianas e intravítreas.

Palabras clave: Síndrome Vogt-Koyanagi-Harada. Edema macular. Optical coherence tomography. Terapia antiangiogénica. Ranibizumab.

Date of reception: 20-05-2016

Date of acceptance: 05-07-2016

E-mail: dra_floresperaza@yahoo.com; DOI: 10.24875/RMOE.M18000035
Available online: 01-11-2018 RevMex Oftalmol (Eng).2018;92(6):265-269 www.rmo.com.mx the CC BY-NC-ND 


\section{Introduction}

Vogt-Koyanagi-Harada syndrome, also known as the uveo-meningeal syndrome, is a bilateral, diffuse granulomatous panuveitis that presents with serous retinal detachment and may be accompanied by central nervous system involvement, dermatological and auditory alterations'.

The evolution of the disease comprises four clinical stages: prodromal, acute uveitic, convalescent and chronic recurrent ${ }^{1}$.

The chronic recurrent stage of our patient, takes place between months-years after the uveitic stage, interrupting the convalescent stage. This stage is not present in all patients. It characterizes by episodes of granulomatous anterior uveitis frequently resistant to steroid treatment. Rarely, it is associated with posterior uveitis. Characteristically, iris nodules usually appear'.

It is the stage of chronic complications, such as cataracts, glaucoma, macular edema, choroidal and papillary neovascularization and subretinal neovascular membrane ${ }^{2}$.

Fifty percent of patients show complications that include: cataract formation in approximately $11-38 \%$ of patients; glaucoma in $40 \%$ of patients, both acute angle-closure by anterior displacement of the iris-lens complex or by the formation of posterior synechiae and peripheral anterior synechiae, and chronic open-angle glaucoma due to prolonged use of glucocorticoids; choroidal neovascular membranes in $5-10 \%$ of cases, subretinal fibrosis and extensive chorioretinal atrophy?

Neovascularization in these patients occurs due to both sustained inflammation and choroidal ischemia.

\section{Case presentation}

A 39-year-old female born in the state of Hidalgo, resident of Mexico City, with no relevant hereditary background.

History of incomplete type II Vogt-Koyanagi-Harada syndrome, with bilateral serous retinal detachment, tinnitus and vertigo; one year ago, she was treated with azathioprine, folic acid and prednisone.

She attended the clinic due to a new episode of visual loss in both eyes of 2 months of evolution, accompanied by metamorphopsia, without systemic symptoms.

Visual acuity (VA) in the right eye was $20 / 200$, which improved with pinhole to $20 / 100$, and intraocular pressure was $12 \mathrm{mmHg}$; anterior segment showed fine retrokeratic deposits without cells in the anterior chamber, Vossius ring and lens with posterior subcapsular opacity. The posterior pole showed loss of foveolar brightness.

In the left eye, VA 20/100 that improved with pinhole to 20/70, anterior segment with Vossius ring, lens with posterior subcapsular opacity. Posterior pole showed loss of foveolar brightness.

Optical coherence tomography (OCT) was performed before initiating treatment (Fig. 1).

Given the findings, an intravitreal injection of $0.5 \mathrm{mg}$ ranibizumab (Lucentis ${ }^{\circledR}$ ) was applied in both eyes, improving VA at 2 weeks and reaching a VA in the right eye of 20/70 that improved with pinhole to $20 / 50$ and in the left eye of 20/70 that improved to $20 / 40$.

Due to the findings in a follow-up OCT (Fig. 2), a new dose of ranibizumab (Lucentis ${ }^{\circledR}$ ) was applied, achieving a visual improvement in the right eye to 20/50 (20/40 with pinhole) and in the left eye to $20 / 40$ (20/30 with pinhole).

After the application of the initial injection and at 4 weeks, retinal thickness decreased significantly (Fig. 3).

The evolution of the patient was always towards improvement, with changes in macular edema by OCT after the application of antiangiogenic agents (Fig. 4).

Currently, 6 months starting therapy, the patient has the same VA, without relapses and side effects.

\section{Discussion}

Macular edema is observed clinically as a thickening of the layers of the retina secondary to an abnormal accumulation of fluids. From a physiopathological point of view, it is due to the disruption of the balance between the hydrostatic forces in the capillaries and the tissue osmotic pressure gradients, which favor the diffusion of liquids to nearby tissues. The increase in plasma proteins, with the corresponding increase in osmotic pressure, determines intravascular, intercellular and intracellular fluid changes. Within the eye, the existence of the blood-retinal barrier, whose internal part is constituted by the capillaries of the retina, favors, in the presence of capillary alterations, fluid leakage due to hydrostatic or osmotic gradient changes ${ }^{3}$.

The abnormal vascular permeability of the retina induces macular edema, which is the main cause of visual loss in diseases such as diabetic retinopathy, exudative macular degeneration, retinal vascular occlusions and various inflammatory and neoplastic conditions. However, other processes lead to increased vascular permeability through different mechanisms. Vascular endothelial growth factor (VEGF) activates vascular loss pathways, and its levels correlate with 


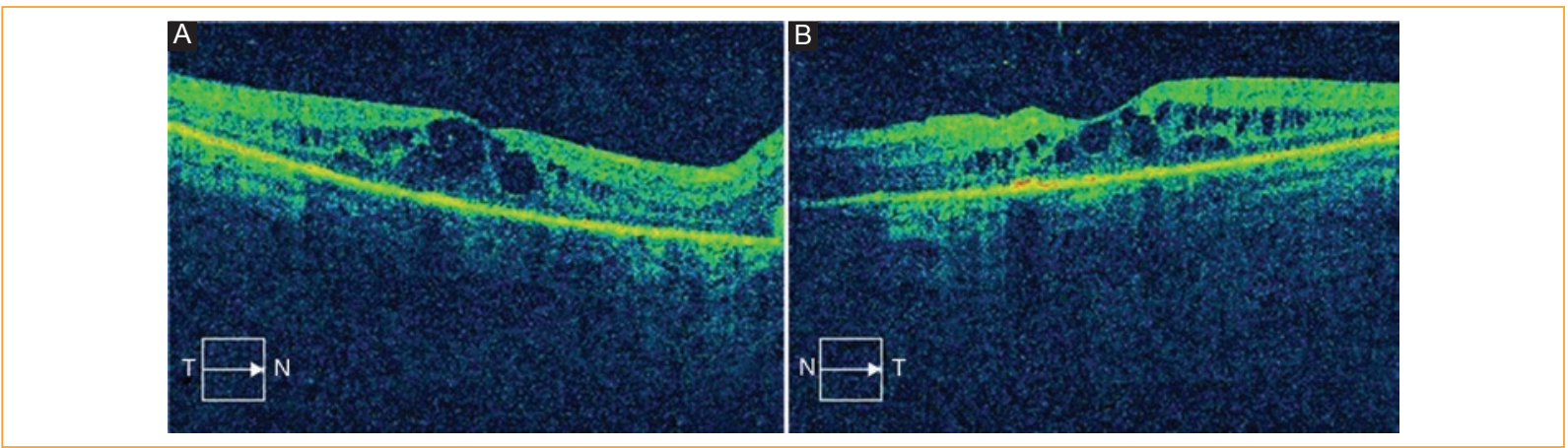

Figure 1. A: OCT OD. Macular edema, 426 microns. VA 20/200. Pre-treatment B: OCT OS. Macular edema, 359 microns. VA 20/100. Pre-treatment.

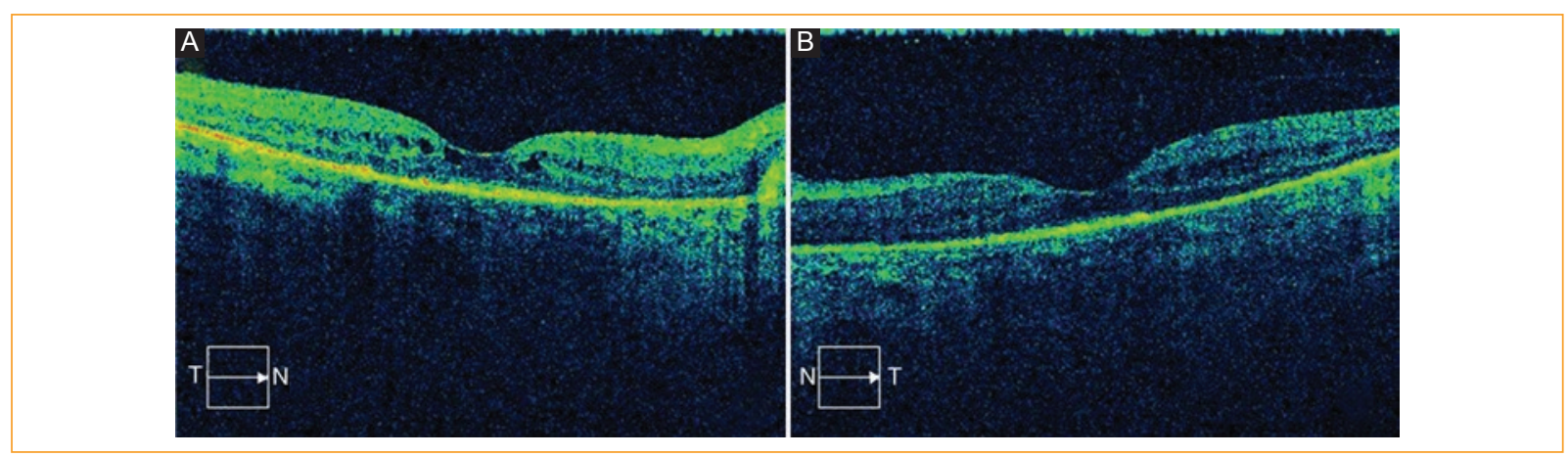

Figure 2. A: OCT OD. Macular edema, 238 microns. VA 20/70. After ranibizumab injection, first dose. B: OCT OS. Macular edema, 209 microns. VA 20/70. After ranibizumab injection, first dose.

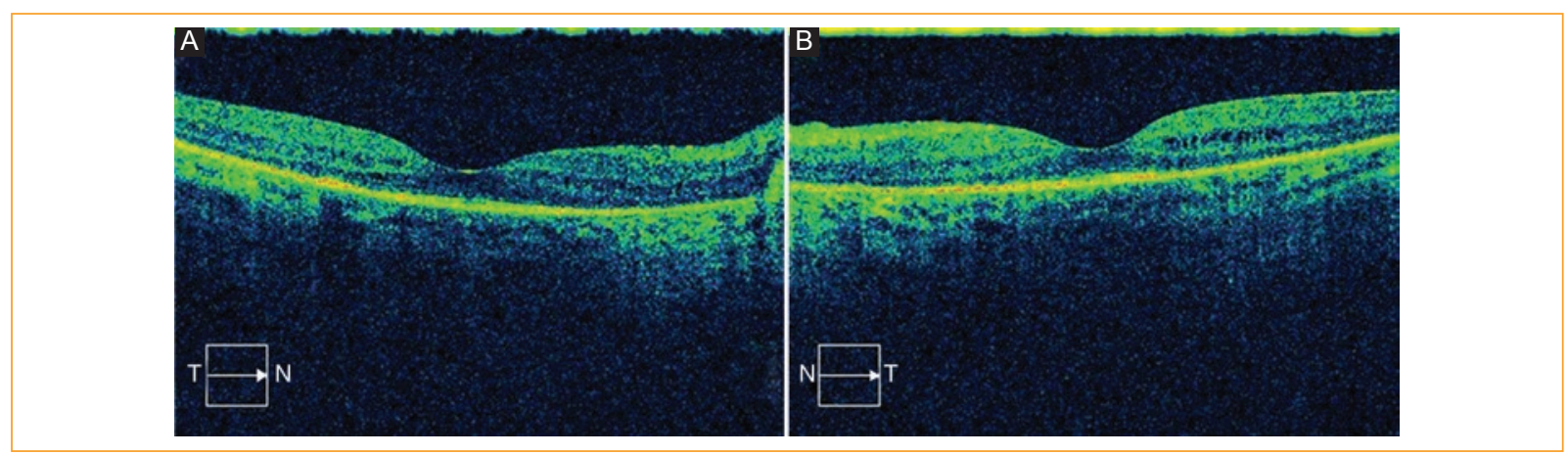

Figure 3. A: OCT OD. Macular edema, 211 microns. VA 20/40. After ranibizumab injection, second dose. B: OCT OS. Macular edema, 170 microns. VA 20/40. After ranibizumab injection, second dose.

increased ischemic vascular permeability in retinopathies and possibly also in exudative macular degeneration and uveitis ${ }^{4}$.

Macular edema is relatively rare in Vogt-Koyanagi-Harada syndrome, in contrast to other chronic intraocular inflammation syndromes. It is a rare cause of late visual loss, and may be the result of capillary leakage from the parafoveal area or fluid leakage at the level of the retinal pigment epithelium.
One of the key players in angiogenesis regulation is VEGF and its biological activity. This growth factor promotes endothelial cell proliferation, and increases vascular permeability and ocular inflammation ${ }^{5}$.

VEGF is a dimeric glycoprotein that under hypoxic conditions is secreted by pericytes, pigmented epithelial cells of the retina and glial cells (Müller cells) 6 . VEGF directly stimulates the development of the internal and external vasculature of the eye, and acts as a vascular 


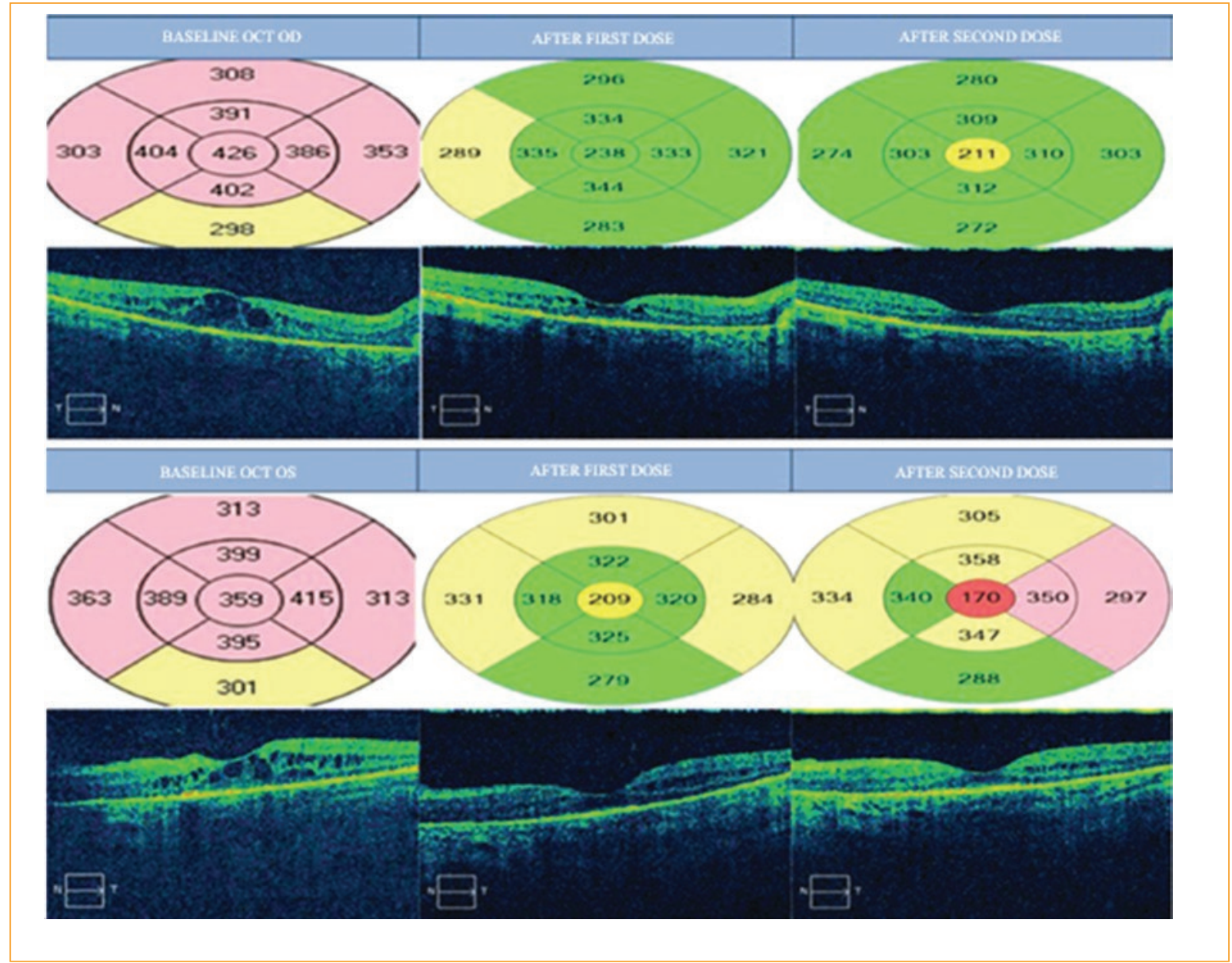

Figure 4. This table shows the evolution of macular edema in both eyes, showing macular thickness values and tomographic images. The first column shows the images when the condition started and diagnosis was made. The second column shows the images after the application of the first dose of ranibizumab (Lucentis ${ }^{\circledR}$ ) with less macular thickening and fewer cystic spaces. The third column shows the result after the second application of the antiangiogenic drug.

permeability factor ${ }^{7}$. Its isoforms with biological activity are $121,165,189$ and 206 . Its activity is mediated by two high-affinity receptor tyrosine kinases: the VEGFR receptor $\left(\mathrm{FLT}_{1}\right)$ and the VEGFR 2 receptor $\left(\mathrm{FLT}_{2}\right)^{8}$.

In general, under physiologic conditions there is a balance between the promoters and the inhibitors of angiogenesis. However, when the balance is disrupted, as happens during episodes of hypoxia or inflammation, there is a shift towards the formation of abnormal vessels ${ }^{9}$.

Modern anti-angiogenic therapy aims to inhibit the production or the biological effects of all the molecules involved, especially VEGF ${ }^{10}$.

In our patient, we used ranibizumab (Lucentis, Genentech/Novartis ${ }^{\circledR}$ ) as antiangiogenic therapy, which is a recombinant Fab fragment synthesized from bevacizumab that binds to all the active isoforms of VEGF. It is effective for the treatment of choroidal neovascularization secondary to age-related macular degeneration and macular edema. It has been approved for clinical use since June $2006^{11,12}$.

\section{Conclusions}

There are studies that show that treating this type of edema with injections of sub Tenon and intravitreal steroids improves VA in two or more lines in the Snellen chart. Studies that evaluate the efficacy of intravitreal antiangiogenics show improvements of at least 2 lines; however, our patient obtained a better response improving 4 lines with a decrease in retinal thickness of more 
than 200 microns in the right eye and more than 150 microns in the left eye.

\section{Ethical disclosures}

Protection of human and animal subjects. The authors declare that no experiments were performed on humans or animals for this study.

Confidentiality of data. The authors declare that no patient data appear in this article.

Right to privacy and informed consent. The authors declare that no patient data appear in this article.

\section{Funding}

The authors received no specific funding for this work.

\section{Conflicts of interest}

The authors declare no conflict of interest.

\section{References}

1. Riveros Frutos A, Romera Romero P, Holgado Pérez S, et al. Enfermedad de Vogt-Koyanagi-Harada. Semin Fund Esp Reuma-tol. 2012;13:142-6.

2. Tsai JH, Evans M, Rao NA. Comparative study of two sets of criteria for the diagnosis of Vogt-Koyanagi-Harada disease. Am J Ophthalmol. 2006;141:778-9

3. Tranos PG, Wickremasinghe SS, Stangos NT, et al. Macularedema. Surv Ophthalmol. 2004:49:470-90.

4. Davis MD, Fisher MR. Diabetic macular oedema. Am J Ophthal-mol. 2003; $110: 77-82$

5. Kowanetz M, Ferrara N. Vascular endothelial growth factor sig-naling pathways: Therapeutic perspective. Clin Cancer Res. 2006;12:5018-22.

6. Madanlou HD, Gharraee Z, Hasan J, et al. Ontogeny of VEGF, IGF-I and $\mathrm{GH}$ in neonatal rat serum, vitreous fluid, and retina from birth to weaning. Invest Ophthalmol Vis Sci. 2006;47:738-44.

7. Kvanta A. Ocular angiogenesis: The role of growth factors. Acta Ophthalmol Scand. 2006;84:282-8.

8. Yoo $\mathrm{MH}$, Hyun $\mathrm{HJ}$, Kob JY, et al. Riluzole inhibits VEGF-inducedendothelial cell proliferation in vitro and hyoeroxia-inducedabnormal vessel formation in vivo. Invest Ophthalmol Vis Sci. 2005;46:4780-7.

9. Hutcheson KA. Retinopathy of prematurity. Curr Opin Ophthal-mol. 2003;14:286-90.

10. Manzano RP, Peyman GA, Khan P, et al. Testing intravitreal toxi-city of bevacizumab (Avastin). Retina. 2006;26:257-61.

11. Dorrell $M$, Uusitalo-Jarvinen $H$, Aguilar $E$, et al. Ocular neovas-cularization: Basic mechanisms and therapeutic advances. SurvOphthalmol. 2007;52:S3-19.

12. Heier JS, Antoszyk AN, Pavan PR, et al. Ranibizumab for treat-ment of neovascular age-related macular degeneration: A phasei/ii multicenter, controlled, multidose study. Ophthalmology.2006;113:642-4 